\title{
Tratamento de águas amarelas em leito filtrante intermitente de carvão ativado
}

Treatment of yellow waters in intermittent percolation filter beds filled with activated carbon

\author{
Pablo Luiz Fernandes Guimarães', Rui de Oliveira² , Mônica de Amorim³ , Narcísio Cabral de Araújo4, \\ Andréa Carla Lima Rodrigues ${ }^{5}$ \\ 1,4 Mestre em Engenharia Civil e Ambiental - Universidade Federal de Campina Grande \\ 2,3,5 Professores do Programa de Pós-Graduação em Engenharia Civil e Ambiental - Universidade Federal de Campina Grande
}

\begin{abstract}
Resumo
O presente trabalho tem o objetivo de estudar o desempenho de um leito percolador (filtro) intermitente, preenchido com carvão ativado granulado, no tratamento de águas amarelas, a fim de verificar o potencial desta tecnologia como parte integrante de sistemas ecológicos descentralizados de tratamento de águas residuárias. Para verificar a eficiência do filtro o afluente e o efluente tratado foram caracterizados por meio de indicadores físicos, químicos e microbiológico. O filtro apresentou bom desempenho na recuperação de nitrogênio, produzindo um efluente bem nitrificado com excelente qualidade estética, ausência de indicadores de contaminação fecal e sem risco de sodificação do solo. Portanto, o efluente obtido pelo tratamento de águas amarelas no filtro com leito de carvão ativado granular parece ser um excelente fertilizante natural, proporcionando uma recirculação significativa de nutrientes.
\end{abstract}

Palavras-chaves: Filtração intermitente, Carvão ativado granulado, Saneamento ecológico, Reuso agrícola

\begin{abstract}
The present work aims to study the performance of intermittent percolation beds (filter), filled with granular activated carbon, treating yellow waters in order to verify the potential of this technology as part of decentralized ecological systems of wastewater treatment. To verify the efficiency of filter the influent and treated effluent were characterized by physical, chemical and microbiological parameters. The filter filled with granular activated carbon showed a good performance in nitrogen recovery aside producing a well nitrified effluent with very good aesthetic quality, absence of faecal contamination indicators and without soil sodium hazard. Therefore, effluents of filters filled with activated carbon treating yellow waters appear to be an excellent natural fertilizer providing a significant recirculation of nutrients.
\end{abstract}

Keywords: Intermittent filtration, Granular activated carbon, Ecological sanitation, Agricultural reuse 


\section{INTRODUÇÃO}

Os sistemas convencionais de esgotamento sanitário baseiam-se no tratamento das águas residuárias em estações centralizadas, as quais são caracterizadas pelo elevado custo de construção, operação e manutenção. Além disso, promovem a mistura dos vários tipos de efluentes, dificultando o tratamento e, frequentemente, inviabilizando o reuso, criando um fluxo linear de matérias e nutrientes que comprometem a qualidade dos recursos hídricos. Diante dessas desvantagens se faz importante o estudo de caminhos alternativos aos sistemas convencionais de esgotamento sanitário que possuam tratamento e reuso in loco através da segregação dos vários tipos de efluente e descentralização dos sistemas de tratamento.

No âmbito das águas residuárias domésticas, segundo Magri et al. (2008), podem ser segregadas as águas cinzas (lavatório, chuveiro, tanque e máquina de lavar roupas) e águas negras (pia de cozinha e vaso sanitário), e estas ainda em águas marrons (vaso - fezes) e águas amarelas (vaso - urina). São denominadas águas amarelas, as águas residuárias geradas em mictórios ou em vasos sanitários com compartimentos separadores para coleta de urina, ou seja, a urina é o componente principal deste resíduo líquido, além da própria água utilizada no aparelho sanitário para o transporte desta excreta para a rede coletora (COSTANZI et al., 2010).

As águas amarelas representam cerca de $1 \%$ do volume do esgoto doméstico e contribuem com aproximadamente $80 \%$ do nitrogênio, $55 \%$ do fósforo e $60 \%$ do potássio presentes no esgoto doméstico (JÖNSSON, 2002). Num cenário ideal de total reaproveitamento, poder-se-ia conseguir uma economia de $36 \%$ de energia, a qual deixaria de ser utilizada nas estações de tratamento de esgoto e na produção de fertilizantes, uma redução de até $25 \%$ no uso de fertilizantes comerciais e uma redução na emissão de gases (NH3) que contribuem indiretamente para a intensificação do efeito estufa (LIND et al., 2001; JÖNSSON, 2002).

O esgotamento sanitário ecológico propõe a gestão descentralizada dos esgotos sanitários, capaz de proporcionar a separação, tratamento e reuso in loco do efluente, eliminando a etapa de transporte que, na maioria das vezes, onera e inviabiliza o reuso. A descentralização está sendo cada vez mais reconhecida como um modelo sustentável de gerenciamento de esgotos domésticos, com potencial para ampliar o acesso da população mundial ao abastecimento de água e ao saneamento adequado e, concomitantemente, aumentar a eficiência de tratamento, possibilitando o reuso do efluente (LIBRALATO et al., 2012).

A filtração intermitente se enquadra no contexto de descentralização uma vez que se apresenta como uma alternativa simples de fácil instalação, operação e manutenção, de baixo custo e de conhecimento amplamente difundido entre os técnicos. Além disso, é uma tecnologia de tratamento ideal para as condições de regime hidráulico características de sistemas descentralizados, os quais apresentam baixas cargas hidráulicas e grandes variações de vazão (LIMA, 2008).

Neste contexto este trabalho se propôs a estudar o tratamento de águas amarelas geradas em mictórios, mediante o emprego da técnica de percolação em um filtro intermitente, analisando a qualidade do efluente obtido, a fim de verificar o potencial desta tecnologia como parte integrante de sistemas ecológicos descentralizados de tratamento de águas residuárias.

\section{METODOLOGIA}

O projeto foi desenvolvido em escala-piloto, no Laboratório de Saneamento da Universidade Federal de Campina Grande, tendo sido confeccionado um filtro em tubo de PVC com diâmetro interno de $100 \mathrm{~mm}$ e altura total de $1 \mathrm{~m}$. O filtro era aberto na parte superior e fechado na parte inferior com um CAP de PVC de $100 \mathrm{~mm}$ com um pequeno orifício, onde foi instalada a tubulação (Figura 1D) de saída do efluente.

Logo acima um reservatório para o afluente constituído de uma garrafa PET de 1,5 L (Figura 1A) e uma pinça rolete (Figura 1B) com regulagem precisa permitiu um excelente controle e manutenção de gotejamento para controlar a vazão de alimentação. Na parte lateral inferior do filtro foi instalado um tubo de PVC flexível (Figura 1C) com diâmetro interno de $15 \mathrm{~mm}$ para proporcionar entrada de ar. A base do filtro foi preenchida com $5 \mathrm{~cm}$ de brita com granulometria de 12 a $25 \mathrm{~mm}$ e logo acima 
uma camada de $10 \mathrm{~cm}$ de brita com granulometria de 2,4 a 9,5 $\mathrm{mm}$. Esse material teve o objetivo de sustentar o meio filtrante e impedir que partículas fossem arrastadas junto com o efluente. Para impedir que a porção superior do leito perdesse sua uniformidade, devido ao impacto do afluente, foi disposta acima do leito filtrante uma camada de $5 \mathrm{~cm}$ de brita com granulometria de 12 a $25 \mathrm{~mm}$.
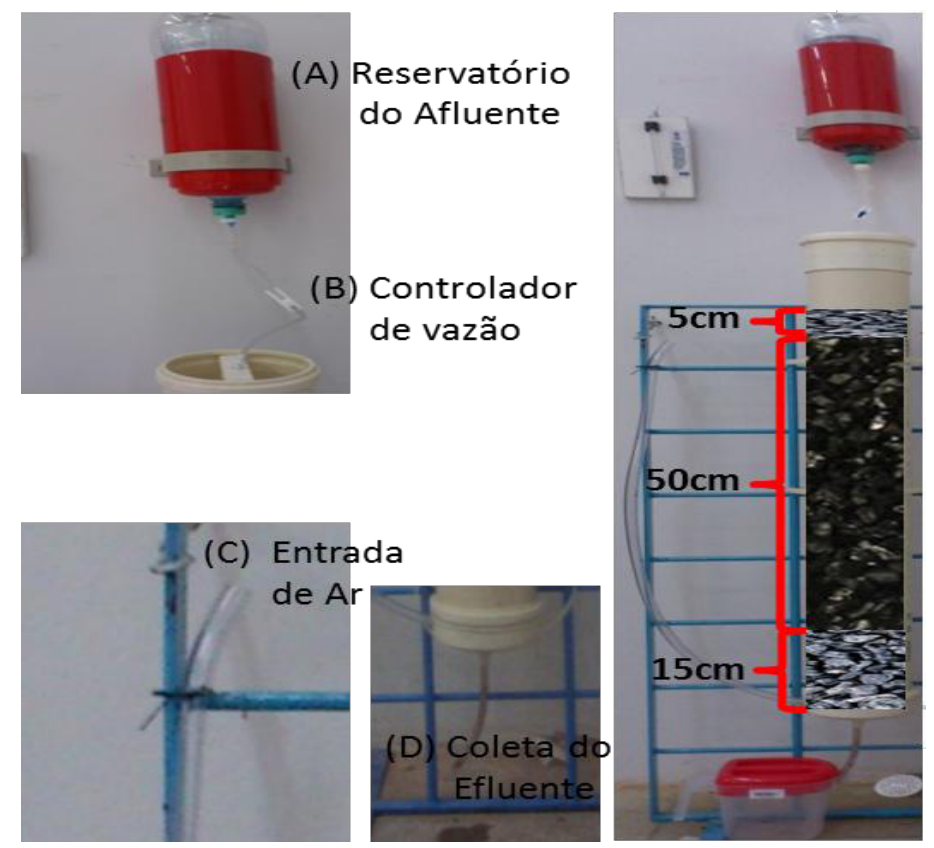

Figura 1: Ilustração dos componentes do sistema experimental

O meio filtrante foi constituído de uma camada de $50 \mathrm{~cm}$ de carvão ativado granular (CAG) vegetal originário da casca de coco de dendê de 8 x 30 mesh que foi adquirido junto à CARBONMAR COM. E IND. DE CARVÃO ATIVADO LTDA. Sua caracterização (apresentada na Tabela 1) foi realizada nas dependências do Laboratório de Desenvolvimento de Novos Materiais (LabNov) e do Laboratório de Engenharia de Pavimentos (LEP) da Universidade Federal de Campina Grande.

Tabela 1: Caracterização do carvão ativado utilizado

\begin{tabular}{|c|c|}
\hline Parâmetro & Valor \\
\hline Massa & $2,353 \mathrm{~kg}$ \\
\hline Altura do meio & $50 \mathrm{~cm}$ \\
\hline Granulometria & $0,6-2,36 \mathrm{~mm}$ \\
\hline Diâmetro efetivo $\left(\mathrm{D}_{10}\right)$ & $0,49 \mathrm{~mm}$ \\
\hline $\begin{array}{l}\text { Coeficiente de uniformidade } \\
\qquad\left(\mathrm{D}_{60} / \mathrm{D}_{10}\right)\end{array}$ & 2,71 \\
\hline Superfície específica BET & $673,7 \mathrm{~m}^{2} \mathrm{~g}^{-1}$ \\
\hline Volume de microporos & $0,347 \mathrm{~cm}^{3} \mathrm{~g}^{-1}$ \\
\hline Área de microporos & $488,1634 \mathrm{~m}^{2} \mathrm{~g}^{-1}$ \\
\hline Tamanho médio dos microporos & $20,6574 \AA$ \\
\hline Número de iodo & Mínimo $900 \mathrm{mg} \mathrm{g}^{-1}$ \\
\hline Índice de azul de metileno & 120 a $250 \mathrm{mg} \mathrm{g}^{-1}$ \\
\hline
\end{tabular}


O filtro foi operado de modo a manter condição aeróbia no seu interior. Para tanto, a aplicação do afluente foi feita de modo intermitente, permitindo reaeração do leito. Para ampliar a aeração do leito, foi instalado na lateral de cada filtro um tubo de PVC flexível para a captação de ar de forma natural, não existindo qualquer equipamento mecânico com a finalidade de cumprir tal função.

Por não existirem norma técnicas para filtros que tratam este tipo de efluente, a taxa de aplicação de $100 \mathrm{~L} \mathrm{dia}^{-1} \mathrm{~m}^{-2}$, foi baseada na NBR 13969/97 (ABNT, 1997), que dispõe sobre a aplicação direta de efluentes de tanques sépticos em filtros de areia. Como o filtro tem uma área superficial de 0,0079 $\mathrm{m}^{2}$ e a taxa de aplicação foi de $100 \mathrm{~L}$ dia- $1 \mathrm{~m}^{-2}$, resultou num volume de $790 \mathrm{~mL}$ de afluente que foi aplicado diariamente, com fluxo descendente, num período de $7 \mathrm{~h}$ com uma vazão de $1,9 \mathrm{~mL} \mathrm{~min}^{-1}$.

O afluente aplicado no filtro foi obtido através da coleta de urina entre voluntários do sexo masculino entre 15 e 60 anos, e, em seguida era diluída em água de abastecimento até uma concentração final de $7,3 \%$ de urina na mistura. Tal concentração é representativa de águas amarelas geradas em mictórios e foi estimada, como mostra a Tabela 2, com base no levantamento bibliográfico de normas, trabalhos acadêmicos e fabricantes de mictórios com base nos volumes de água gasto e de urina excretada.

Tabela 2: Estimativa da concentração de urina no efluente de mictório

\begin{tabular}{|c|c|c|c|c|}
\hline \multicolumn{5}{|c|}{ Estimativa da produção de urina por cada micção } \\
\hline & L. pes $^{-1} \cdot d^{-1}$ & \multicolumn{2}{|c|}{$\mathrm{mL}$ micção ${ }^{-1(\mathrm{~A})}$} & mL. micção $0^{-1(B)}$ \\
\hline Fittscher \& Hahn (1998) & 1,57 & \multicolumn{2}{|c|}{196} & 224 \\
\hline Rauch (2003) & 1,5 & \multicolumn{2}{|c|}{188} & 214 \\
\hline Bazzarella et al. (2005) & 1,04 & \multicolumn{2}{|c|}{130} & 149 \\
\hline Zancheta (2007) & 1,18 & \multicolumn{2}{|c|}{148} & 169 \\
\hline Sousa (2008) & 1,19 & \multicolumn{2}{|c|}{149} & 170 \\
\hline Rios (2008) & 1,46 & \multicolumn{2}{|c|}{183} & 209 \\
\hline Soares (2011) & & \multicolumn{2}{|c|}{217} & 217 \\
\hline Média & & \multicolumn{2}{|c|}{169} & 190 \\
\hline \multicolumn{2}{|c|}{ Consumo de água por uso em mictórios } & \multicolumn{3}{|c|}{$\begin{array}{l}\text { Porcentagem de urina no efluente dos mictórios } \\
\qquad(\%)\end{array}$} \\
\hline & L. uso $^{-1}$ & Por micçã & lia ${ }^{(A)}$ & Por micção média ${ }^{(B)}$ \\
\hline NBR 5626 & 5 & & 3,3 & 3,7 \\
\hline NBR 13713 / NBR 5626 & 1,5 & & 10,1 & 11,2 \\
\hline Oliveira (1999) & 1,63 & & 9,4 & 10,4 \\
\hline ANA (2005) & 1,8 & & 8,6 & 9,5 \\
\hline SABESP (2013) & 4 & & 4,1 & 4,5 \\
\hline DRACO (2013) & 2 & & 7,8 & 8,7 \\
\hline \multirow[t]{2}{*}{$\begin{array}{c}\text { DECA (2013)/Perona (2011)/ AL } \\
\text { CORRAL (2013) }\end{array}$} & \multirow[t]{2}{*}{2,5} & & 6,3 & 7,1 \\
\hline & & Média & $6,9 \%$ & $7,7 \%$ \\
\hline
\end{tabular}

Onde (A) e (B) são os volumes e a porcentagens de urina calculados a partir da frequência de 7 micções diárias relatada por Vinnerås (2006) e de 8 micções por Soares (2011) e Zancheta (2007), respectivamente.

Para avaliar o desempenho do filtro foram realizadas aproximadamente 3340 análises no afluente e efluente, abrangendo variáveis de natureza física (cor aparente, turbidez e condutividade elétrica), química (alcalinidade total, nitrogênio, fósforo, sódio, cálcio, potássio, magnésio, dureza, DQO e oxigênio dissolvido) e microbiológica (coliformes termotolerantes). Todas as análises foram realizadas de acordo com o Standard Methods for the Examination of Water and Wastewater (APHA, AWWA, WEF, 1998).

O filtro foi operado do dia 6/5/2013 até o dia 4/10/2013, sendo, nessa data, observado um 
aumento significativo da perda de carga devido à colmatação do meio poroso que teve, como consequência, a diminuição da velocidade de escoamento e o acúmulo de afluente acima do leito de percolação.

\section{RESULTADOS E DISCUSSÃO}

Os resultados das análises físico-químicas e microbiológicas realizadas nas amostras de águas amarelas aplicadas como afluente do leito percolador intermitente são apresentados na Tabela 3. Foi observada significativa discrepância entre os valores máximos e mínimos dos indicadores analisados. Este fato se deve à variação da concentração dos constituintes da urina humana, causada por fatores climáticos, fisiológicos, dieta e atividades praticadas de cada indivíduo.

Tabela 3: Caracterização das águas amarelas afluentes

\begin{tabular}{|c|c|c|c|c|c|c|}
\hline Parâmetro & $\mathbf{n}$ & $\begin{array}{l}\text { Valor } \\
\text { médio }\end{array}$ & $\begin{array}{l}\text { Valor } \\
\text { mínimo }\end{array}$ & $\begin{array}{l}\text { Valor } \\
\text { máximo }\end{array}$ & $\begin{array}{l}\text { Desvio } \\
\text { padrão }\end{array}$ & $\begin{array}{c}\text { Coeficiente } \\
\text { de variação } \\
(\%)\end{array}$ \\
\hline pH & 41 & 6,7 & 5,9 & 8,1 & 0,45 & 6,7 \\
\hline Cor $(\mathrm{uC})$ & 35 & 151 & 43 & 500 & 103,7 & 68,6 \\
\hline Turbidez (uT) & 35 & 5,9 & 0,1 & 45 & 10,8 & 184 \\
\hline $\mathrm{CE}\left(\mathrm{mS} \mathrm{cm}^{-1}\right)$ & 47 & 2,3 & 1,7 & 3,5 & 0,49 & 21 \\
\hline Alcalinidade total $\left(\mathrm{mg} \mathrm{CaCO}_{3} \mathrm{~L}^{-1}\right)$ & 33 & 423 & 106 & 1710 & 335,9 & 79 \\
\hline $\operatorname{DQO}\left(\mathrm{mg} \mathrm{L}^{-1}\right)$ & 37 & 892 & 232 & 1560 & 300 & 33,6 \\
\hline $\mathrm{OD}\left(\mathrm{mg} \mathrm{L}^{-1}\right)$ & 30 & 5,8 & 3,8 & 7,9 & 1,1 & 19,2 \\
\hline NTK (mg N-NH $\left.\mathrm{L}^{-1}\right)$ & 40 & 854 & 417 & 1378 & 256,9 & 30 \\
\hline $\mathrm{NH}_{3}\left(\mathrm{mg} \mathrm{N}-\mathrm{NH}_{3} \mathrm{~L}^{-1}\right)$ & 40 & 113 & 27 & 421 & 84,7 & 75 \\
\hline $\mathrm{NO}_{3}\left(\mathrm{mg} \mathrm{N}-\mathrm{NO}_{3} \mathrm{~L}^{-1}\right)$ & 40 & 0 & - & - & - & - \\
\hline $\mathrm{NO}_{2}\left(\mathrm{mg} \mathrm{N}-\mathrm{NO}_{2} \mathrm{~L}^{-1}\right)$ & 40 & 0 & - & - & - & - \\
\hline Ortofosfato (mg P-PO $\left.\mathrm{PL}_{4} \mathrm{~L}^{-1}\right)$ & 17 & 41,7 & 23 & 68,5 & 13,9 & 33,5 \\
\hline C. termotolerantes & 16 & Ausência & - & - & - & - \\
\hline
\end{tabular}

As águas amarelas, de uma maneira geral, apresentam baixa quantidade de sólidos em suspensão, evidenciada pelos resultados de turbidez (valor médio de 5,9 uT); tal característica reduz a possibilidade de uma colmatação física dos leitos percoladores. Em contrapartida, a elevada presença de substâncias dissolvidas, indicada pela cor aparente (valor médio de $151 \mathrm{uC}$ ), aumenta a vulnerabilidade do meio percolador quanto à colmatação química e nem todo tipo de material, por exemplo, a areia, tem uma boa eficiência na remoção da cor do afluente.

Para o tratamento biológico característico de um filtro intermitente, todos os parâmetros analisados são favoráveis ao processo de nitrificação. A grande disponibilidade de nitrogênio, apresentando um valor médio de $854 \mathrm{mgN} \mathrm{L}^{-1}$, associado à relação $\mathrm{DQO} / \mathrm{N}$ que sempre se manteve abaixo de $2 \mathrm{e}$, muitas vezes, abaixo de 1 , permite condições favoráveis para a atividade dos microrganismos nitrificantes. $\mathrm{O} \mathrm{pH}$ (valor médio de 6,7) e alcalinidade total (valor médio de $423 \mathrm{mg} \mathrm{CaCO}_{3} \mathrm{~L}^{-1}$ ) estiveram na faixa ótima, na maioria da vezes entre 6,5 e 8, e concentração superior à mínima recomendada de $50 \mathrm{mg} \mathrm{CaCO}_{3} \mathrm{~L}^{-1}$, respectivamente. As concentrações de oxigênio dissolvido (média de $5,8 \mathrm{mgO}_{2} \mathrm{~L}^{-1}$ ) também apresentaram valores superiores às concentrações mínimas $\left(2 \mathrm{mgO}_{2} \mathrm{~L}^{-1}\right)$ requeridas para uma nitrificação completa.

Com vistas ao reuso em culturas agrícolas é importante destacar a presença considerável de

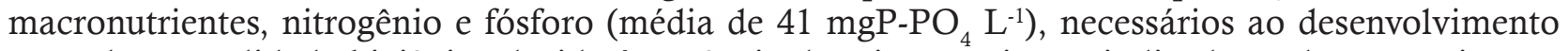
vegetal e a qualidade higiênica devido à ausência de microrganismos indicadores de contaminação fecal. Assim, as águas amarelas podem ser classificadas como fertilizante agrícola natural de grande potencial. 
O filtro com leito de CAG foi eficaz no tratamento físico, devido à sua estrutura microporosa que proporciona uma robusta capacidade de adsorção. A Figura 2 mostra que a remoção da turbidez (em média de 5,9 uT para 1,5 uT) mesmo quando o afluente apresentou valores elevados (por exemplo $45 \mathrm{uT}$ ) tendo o leito de CAG proporcionado um efluente com níveis de turbidez sempre abaixo de $5 \mathrm{uT}$.

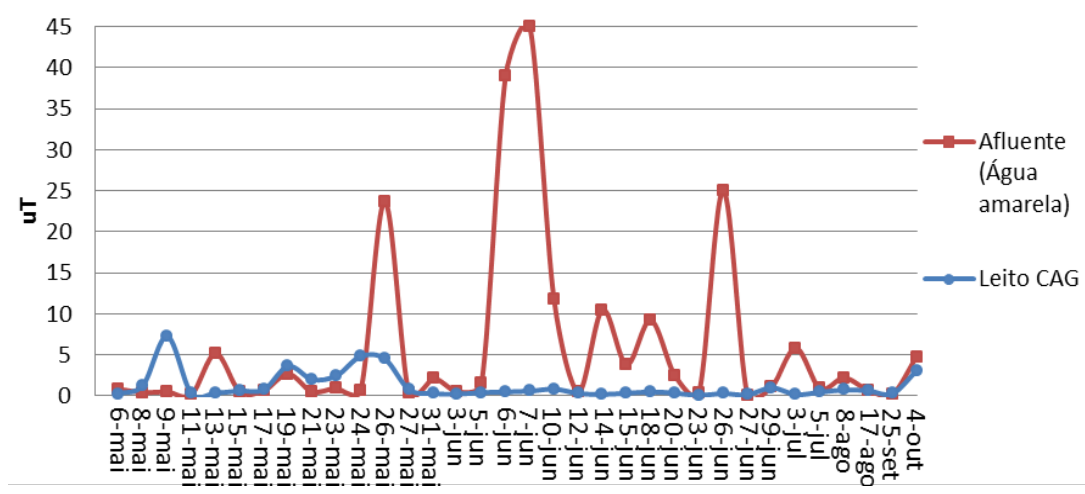

Figura 2: Variação temporal de turbidez do afluente e efluente do leito de CAG

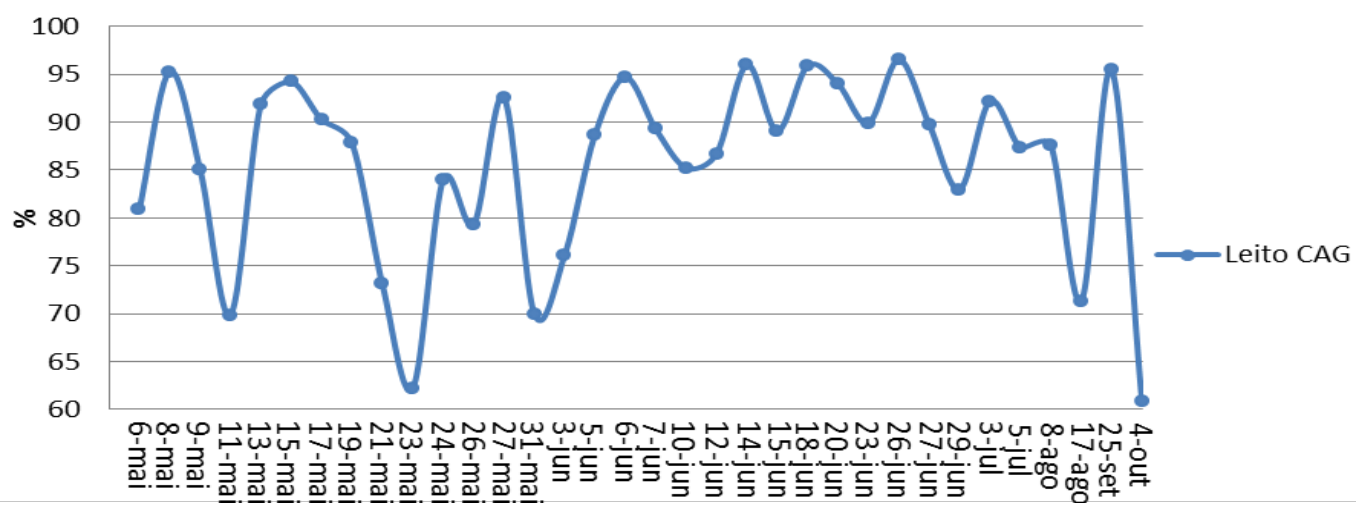

Figura 3: Porcentagem de remoção de cor

Quanto à cor, como mostra a Figura 3, foi observada uma significativa remoção (em média de $151 \mathrm{uC}$ para $16 \mathrm{uC}$ ), com redução mínima de $60 \%$, mas muitas vezes acima de $85 \%$ e chegando até $97 \%$ com relação à cor do afluente. A eficiência no tratamento físico juntamente com a ausência de odor contribui para uma excelente qualidade estética do efluente (Figura 4), tornando-se um aspecto positivo para aceitação da comunidade e usuários que venham adotar este tipo de tratamento.

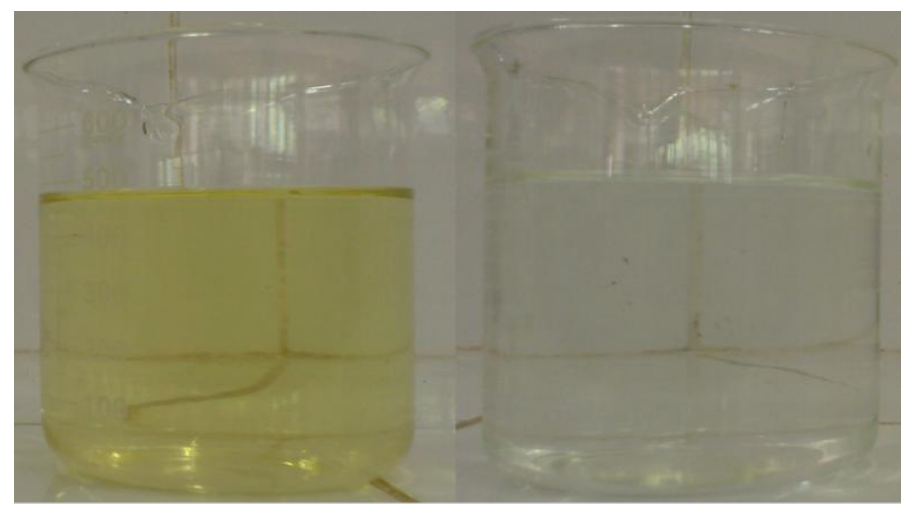

A

B

Figura 4: Afluente (A) e o efluente (B) do filtro com leito CAG 
A remoção de matéria orgânica, em termos de DQO, como ilustrado na Figura 5, no início da operação do filtro de CAG foi de 95 a 99\% e após aclimatação das bactérias nitrificantes a eficiência de remoção diminuiu, uma vez que parte do oxigênio dissolvido disponível foi consumido na oxidação da amônia para nitrato. Entretanto, simultaneamente ao processo de nitrificação, as propriedades adsortivas do CAG proporcionaram uma eficiência de remoção entre 60 e $98 \%$ da DQO do afluente.

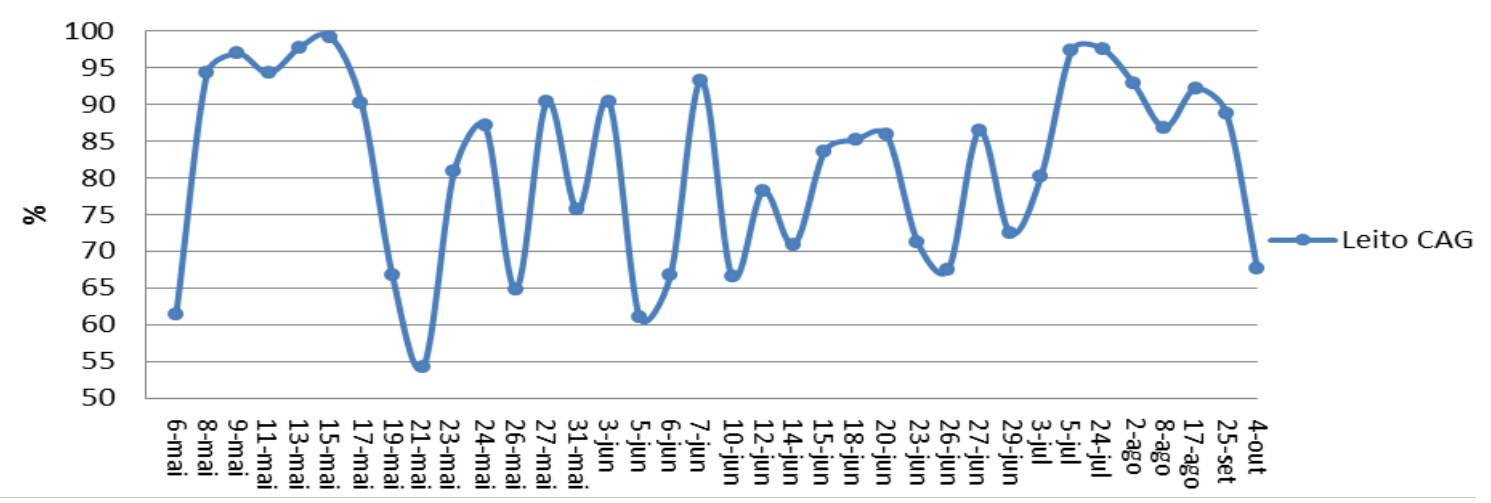

Figura 5: Porcentagem de remoção de DQO

O carvão ativado possui elevada área superficial proporcionando um elevado tempo de contato entre afluente e comunidade biológica, possibilitando a nitrificação de parte da amônia. Consequentemente as frações de nitrogênio presentes no efluente, como ilustrado na Figura 6, estavam na forma de amônio, nitrito e nitrato, em média 241, 104 e $224 \mathrm{mg} \mathrm{N} \mathrm{L}^{-1}$, respectivamente. A nitrificação consumiu grande parte da alcalinidade causando uma leve diminuição de $\mathrm{pH}(5,3$ a 6,5) em relação ao afluente. É importante observar que o nitrogênio amoniacal, devido ao $\mathrm{pH}$ levemente ácido, estava presente em sua forma não volátil, assim todas as formas de nitrogênio eram estáveis.

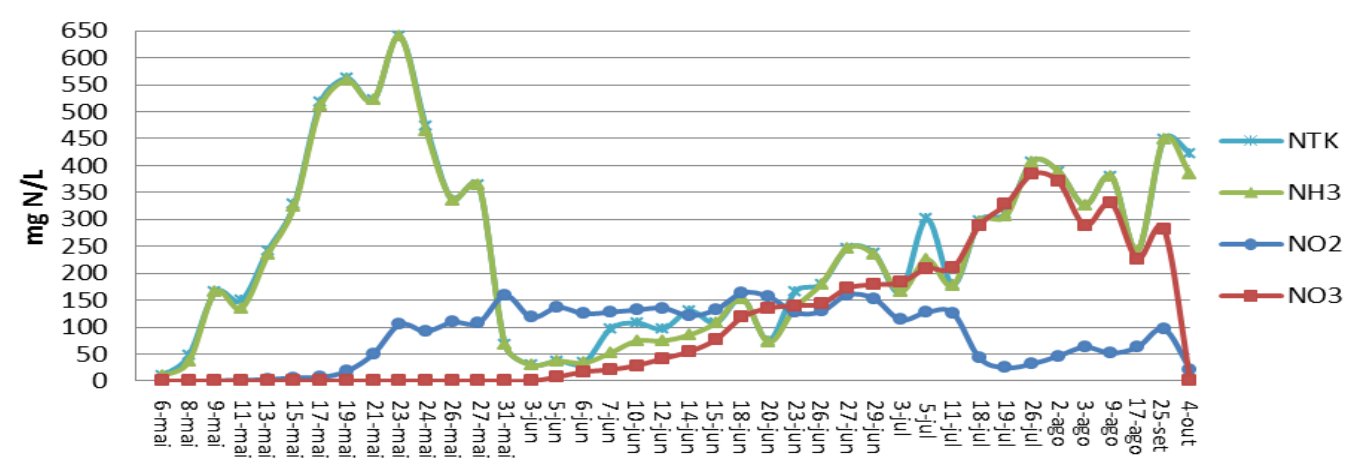

Figura 6: Concentração das frações de nitrogênio no efluente

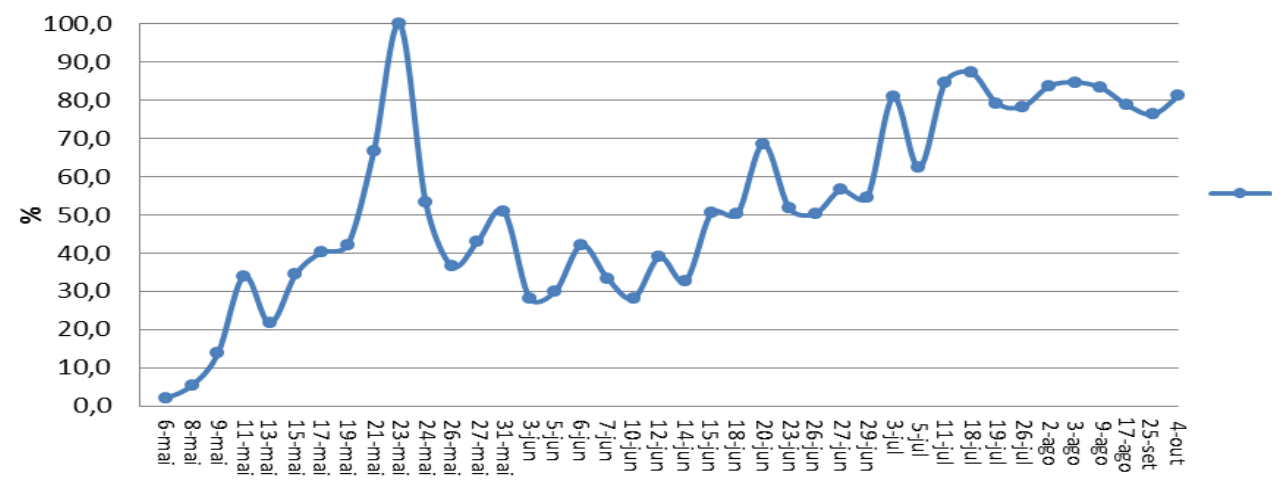

Figura 7: Porcentagem de recuperação do nitrogênio afluente 
A Figura 7 permite verificar que a recuperação de nitrogênio no filtro com leito de CAG, inicialmente, foi abaixo de $50 \%$ devido à adsorção nos microporos. Após a saturação dos microporos e crescimento dos microrganismos nitrificantes a eficiência ficou acima de $50 \%$ e se estabilizou entre 76 e $87 \%$. A elevada eficiência de recuperação e a presença de formas estáveis de nitrogênio (nitrato, nitrito e amônio) proporcionam uma considerável recirculação de nutrientes.

A Figura 8 ilustra o comportamento de ortofosfato no afluente e no efluente do filtro, sendo a redução de 28 a $57 \%$ da concentração de ortofosfato presente no afluente atribuído à assimilação de fósforo no metabolismo bacteriano e à precipitação de cristais de estruvita. Mesmo com este percentual de redução, a quantidade de fósforo remanescente no efluente é significativa para culturas agrícolas.

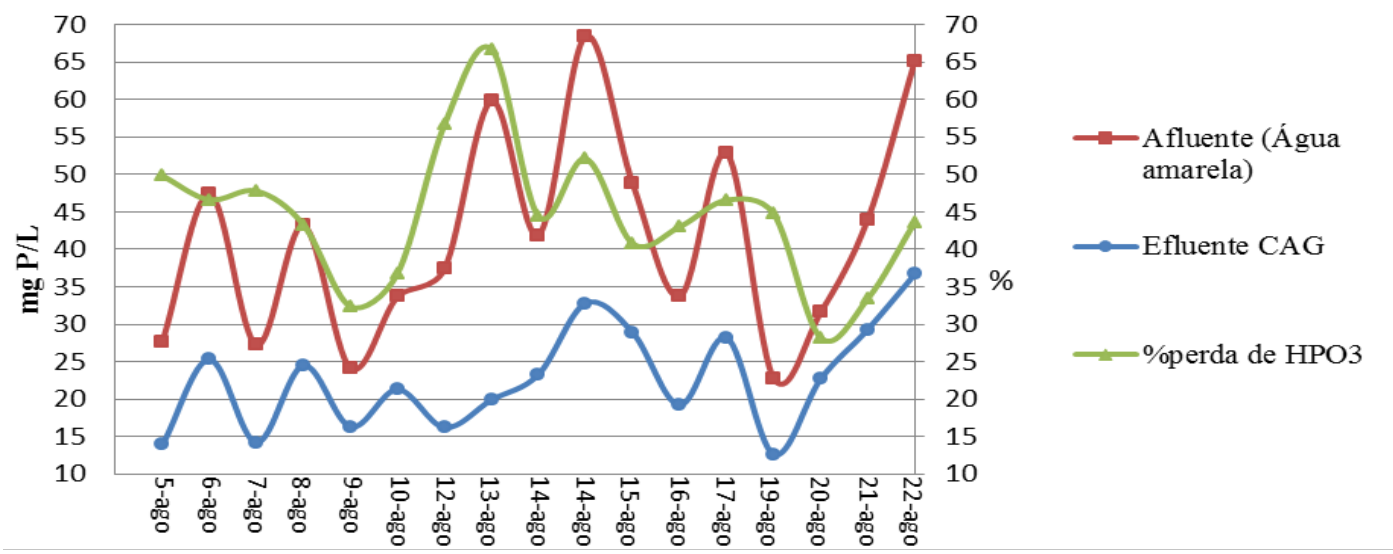

Figura 8: Variação da concentração e redução de ortofosfato

A Tabela 4 mostra o resultado das análises microbiológicas do afluente (água amarela) e efluente do filtro com leito de CAG.

Tabela 4: Análise de coliformes termotolerantes do afluente e efluente do leito de CAG

\begin{tabular}{c|cccc}
\hline Diluição & $\mathbf{n}$ & Afluente (água amarela) & Efluente CAG \\
\hline Bruta & 16 & Ausente & Ausente \\
$\mathbf{1 0}^{-1}$ & 16 & Ausente & Ausente \\
$\mathbf{1 0}^{-2}$ & 16 & Ausente & Ausente \\
$\mathbf{1 0}^{-3}$ & 16 & Ausente & Ausente \\
\hline
\end{tabular}

A razão de adsorção de sódio (RAS), índice que descreve a proporção relativa em que se encontra

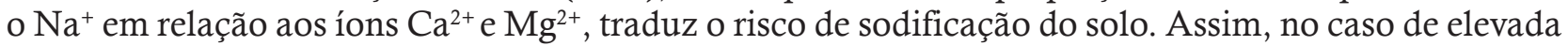
proporção de sódio, os íons $\mathrm{Na}^{+}$são adsorvidos nas partículas do solo, deslocando os íons de cálcio e magnésio, resultando num solo com má drenagem interna que dificulta a absorção de nutrientes e água pelas culturas (AYERS \& WESTCOT, 1985).

A condutividade elétrica é usada como uma medida da concentração de sais dissolvidos, que representa o risco de salinidade para o cultivo. Salinidade excessiva reduz a atividade osmótica de uma planta e assim impede a sua absorção de água e nutrientes do solo, e, portanto, reduz a produtividade das culturas. No entanto, efluentes salinos podem ser utilizados para a irrigação, mesmo que a produtividade da cultura seja reduzida, além do mais, existem culturas (por exemplo algodão) que são tolerantes a médio a altos níveis de salinidade (MARA, 2003).

$\mathrm{Na}$ Tabela 5 são apresentadas as diretrizes para interpretação da qualidade da água utilizada para irrigação, bem como, a equação para o cálculo da RAS. 
Tabela 5: Diretrizes para interpretação da qualidade de água para irrigação

\begin{tabular}{|c|c|c|c|c|}
\hline \multirow{2}{*}{ RAS } & \multirow{2}{*}{$\begin{array}{c}\text { Risco de } \\
\text { sodificação }\end{array}$} & \multirow{2}{*}{$\mathrm{CE}\left(\mathrm{mS} \mathrm{cm} \mathrm{cm}^{-1}\right)$} & \multirow{2}{*}{$\begin{array}{c}\text { Risco de } \\
\text { salinização }\end{array}$} & Cálculo do RAS \\
\hline & & & & \multirow{2}{*}{$\mathrm{RAS}=\frac{\mathrm{Na}^{+}}{\sqrt{\mathrm{Ca}^{2+}+\mathrm{Mg}^{2+}}}$} \\
\hline 0 a 10 & Baixo & 0,1 a 0,25 & Baixo & \\
\hline 11 a 18 & Médio & 0,25 a 0,75 & Médio & \multirow{3}{*}{$\begin{array}{c}\sqrt{2} \\
\text { Onde: } \mathrm{Ca}^{2+}, \mathrm{Mg}^{2+} \mathrm{e} \mathrm{Na}^{+} \\
\text {expressos em meq } \mathrm{L}^{-1} \text {. }\end{array}$} \\
\hline 19 a 26 & Alto & 0,75 a 2,25 & Alto & \\
\hline$>27$ & Muito alto & $>2,25$ & Muito alto & \\
\hline
\end{tabular}

Fonte: Adaptado de Richards (1954).

Os resultados da RAS do efluente do filtro com CAG, como mostrado na Tabela 6, se mantiveram entre 1,3 e 5,2, valores que se enquadram na classificação de baixo risco de sodificação, possibilitando que o efluente seja aplicado para o reuso em culturas agrícolas sem restrição quanto ao risco de impermeabilização do solo.

Tabela 6: Resultado do RAS para o efluente do filtro com CAG

\begin{tabular}{c|ccccccc}
\hline $\mathbf{C E}(\mathbf{m S} / \mathbf{c m})$ & $\mathbf{C a}^{2+}(\mathbf{m e q} / \mathbf{L})$ & $\mathbf{M g}^{2+}(\mathbf{m e q} / \mathbf{L})$ & $\mathbf{N a}^{+}(\mathbf{m e q} / \mathbf{L})$ & $\mathbf{R A S}$ & $\begin{array}{c}\text { Risco } \\
\text { Sodificação }\end{array}$ & $\begin{array}{c}\text { Risco } \\
\text { Salinização }\end{array}$ \\
\hline $\mathbf{4 , 7}$ & 0,6 & 9,7 & 9,5 & $\mathbf{4 , 2}$ & Baixo & Muito alto \\
$\mathbf{4 , 5}$ & 1,8 & 8,2 & 11,7 & $\mathbf{5 , 2}$ & Baixo & Muito alto \\
$\mathbf{4 , 2}$ & 2,8 & 7,6 & 7,4 & $\mathbf{3 , 3}$ & Baixo & Muito alto \\
$\mathbf{4 , 7}$ & 1,2 & 7,9 & 5,5 & $\mathbf{2 , 6}$ & Baixo & Muito alto \\
$\mathbf{4 , 4}$ & 2,0 & 6,2 & 2,5 & $\mathbf{1 , 3}$ & Baixo & Muito alto \\
$\mathbf{4 , 5}$ & 2,3 & 5,5 & 9,2 & $\mathbf{4 , 6}$ & Baixo & Muito alto \\
$\mathbf{4 , 9}$ & 1,8 & 5,6 & 10,0 & $\mathbf{5 , 2}$ & Baixo & Muito alto \\
$\mathbf{5 , 0}$ & 2,8 & 3,8 & 3,0 & $\mathbf{1 , 7}$ & Baixo & Muito alto \\
$\mathbf{4 , 7}$ & 2,4 & 5,6 & 3,1 & $\mathbf{1 , 5}$ & Baixo & Muito alto \\
$\mathbf{4 , 5}$ & 1,6 & 5,9 & 3,9 & $\mathbf{2 , 0}$ & Baixo & Muito alto \\
$\mathbf{4 , 2}$ & 2,6 & 6,0 & 3,0 & $\mathbf{1 , 5}$ & Baixo & Muito alto \\
$\mathbf{4 , 7}$ & 1,6 & 6,6 & 3,1 & $\mathbf{1 , 5}$ & Baixo & Muito alto \\
$\mathbf{4 , 9}$ & 1,8 & 5,8 & 3,1 & $\mathbf{1 , 6}$ & Baixo & Muito alto \\
\hline
\end{tabular}

Com relação ao risco de salinização, apesar dos valores se enquadrarem numa classificação de alto potencial de salinização, esse risco efetivo pode ser reduzido uma vez que as plantas assimilam o nitrato e amônio que são responsáveis pelo aumento da condutividade do efluente, assim como os níveis de condutividade encontrados, entre 4,2 e $5 \mathrm{mS} \mathrm{cm}^{-1}$, são toleráveis por várias culturas agrícolas como mostrado na Tabela 7.

A maioria das pesquisas sobre tratamento de águas amarelas tem como objeto de estudo a urina bruta (sem diluição) e, como resultado, obtêm um efluente com elevada condutividade elétrica ( 49 a $126 \mathrm{mS} \mathrm{cm}^{-1}$ ). Os valores de condutividade elétrica supracitados inviabilizam o reuso do efluente devido ao elevado risco de salinização, fazendo-se necessária a diluição do efluente com água.

Rios (2008) na sua pesquisa utilizando águas amarelas como fonte alternativa de nutrientes em cultivo hidropônico da alface obteve como melhor resultado as soluções nutritivas que eram constituídas de 5 e $10 \%$ de urina tratada por meio da estocagem. Este fato dá grande relevância à fração de água utilizada nos mictórios para o transporte da urina, uma vez que proporciona sua diluição, evitando odores nos banheiros, facilita o tratamento do efluente e dispensa a necessidade de diluição após o tratamento, como evidenciado neste trabalho. 
Tabela 7: Culturas tolerantes a elevada salinidade sem perdas de produtividade

\begin{tabular}{cc}
\hline Cultivo & CE $\mathbf{( m S ~ \mathbf { ~ m } ^ { - 1 } \text { ) }}$ \\
\hline Cevada (Hordeum vulgare) & 5,3 \\
Algodão (Gossypium hirsutum) & 5,1 \\
Beterraba (Beta vulgaris) & 4,7 \\
Sorgo (Sorghum bicolor) & 4,5 \\
Trigo (Triticum aestivum) & 4,0 \\
Agripiro alto (Agropyron elongatum) & 5,0 \\
Agripiro crestado (Agropyron crestatum) & 5,0 \\
Capim-bermuda (Cynodon dactylon) & 4,6 \\
Cevada forrageira (Hordeum vulgare) & 4,0 \\
\hline
\end{tabular}

Fonte: Adaptado de Ayers \& Westcot, (1985).

\section{CONCLUSÕES}

1. O efluente dos mictórios masculinos é objeto importante na abordagem do esgotamento sanitário ecológico, uma vez que possui características adequadas para o reuso em culturas agrícolas devido à elevada concentração de nutrientes, particularmente nitrogênio e fósforo, e ausência de microrganismos indicadores de contaminação fecal.

2. O filtro foi eficiente no tratamento físico proporcionando uma excelente qualidade estética, devido à remoção de cor, turbidez e odor, evitando a rejeição da população, tornando-se um atrativo para utilização do filtro com leito de carvão ativado;

3. A eficiente recuperação de nitrogênio (80\%), em formas estáveis, aliado à ausência de microrganismos indicadores de contaminação fecal e ao baixo risco de impermeabilização do solo, torna o efluente do filtro com leito de carvão ativado um excelente fertilizante natural.

4. O filtro com regime intermitente se mostrou de fácil instalação e operação permitindo enquadrá-lo num cenário de gestão descentralizada das águas residuárias, viabilizando o tratamento e reuso in loco do efluente e, concomitantemente, ampliar o acesso e eficiência dos sistemas de esgotamento sanitário.

5. O filtro com operação intermitente se mostrou eficiente no tratamento de águas amarelas, tornando-o apto a integrar uma estrutura complexa que é proposta pelo esgotamento sanitário ecológico a fim de promover a recirculação de nutrientes das águas residuárias, preservando os recursos hídricos e economizando energia.

\section{REFERÊNCIAS}

ABNT- Associação Brasileira de Normas Técnicas. NBR 13969 - Tanques Sépticos: Unidades de tratamento complementar e disposição final dos efluentes líquidos - Projeto, construção e operação. Rio de Janeiro, 1997.

ABNT- Associação Brasileira de Normas Técnicas. NBR 13713 - Instalações hidráulicas prediais - Aparelhos automáticos acionados mecanicamente e com ciclo de fechamento automático - Requisitos e métodos de ensaio. Rio de Janeiro, 2009.

ABNT- Associação Brasileira de Normas Técnicas. NBR 5626 - Instalação predial de água fria. Rio de Janeiro, 1998.

AL CORRAL. Disponível em: <http://www.alcorral.com.br/economia.asp>. Acessado em: 30/01/2013.

ANA, Agência Nacional das Águas; SAS/ANA, Superintendência de Conservação de Água e Solo; FIESP, 
Federação das Indústrias do Estado de São Paulo; DMA, Departamento de Meio Ambiente e Desenvolvimento Sustentável; SindusCon-SP, Sindicato da Indústria da Construção do Estado de São Paulo; COMASP, Comitê de Meio Ambiente do SindusCon- SP - Conservação e Reuso da Água em Edificações. Prol Editora Gráfica. São Paulo, junho de 2005.

Ayers, R.S.; Westcot, D. W. Water quality for agriculture. Irrigation and Drainage Paper, 29 Rev. 1. Food and Agriculture Organization of the United Nations, Rome, 1985.

BAZZARELLA, B. B.; DIAS, G. B.; BASTOS, F. P.; LEE, P. W.; GONÇALVES, R. F. Caracterização qualiquantitativa da urina humana com vistas ao aproveitamento agrícola. In: Anais do $23^{\circ}$ Congresso Brasileiro de Engenharia Sanitária e Ambiental. ABES, Campo Grande - MS 2005.

COSTANZI, R. N.; FRIZZO, E.; DOMBECK D.; COLLE G.; ROSA J. F. DA; MAIBUK, L. A. C. DO; FERNANDES M. da S. P. Reuso de água amarela. Revista de Engenharia e Tecnologia V. 2, No 1, 2010.

DECA. Disponível em: <http://www.deca.com.br/sustentabilidade/>. Acessado em: 01/02/2013.

DRACO. Válvulas de mictório. Disponível em: <http://www.dracoeletronica.com.br/>. Acesso em: 30/01/2013.

FITTSCHEN, I.; HAHN, H. H. Characterization of the municipal wastewaterpaert human urine and preliminary comparison with liquid cattle excretion. Water science technology, v. 38, n. 6. Alemanha, 1998.

JÖNSSON, H. Urine separating sewage systems - environmental effects and resource usage. Water Science and Technology,v. 46, n. 06-07, 2002.

LIBRALATO, G.; GHIRARDINI, A. V.; AVEZZÙ, F. To centralise or to decentralise: An overview of the most recent trends in wastewater treatment management. Journal of Environmental Management 94, 2012.

LIMA, R. G. Tratamento descentralizado de efluentes como alternativa a despoluição dos recursos hídricos da região metropolitana de Aracaju/SE. Dissertação - Universidade Federal de Sergipe. São Cristóvão, 2008.

LIND, B.; BAN, Z.; BYDÉN, S. Volume reduction and concentration of nutrients in human urine. Ecological Engineering,v. 16, n. 04, 2001.

MAGRI, M. E.; FENELON, F. R.; RABELO, L.; ROSSETO, T. S.; PHILIPPI L. S. Reúso de águas cinzas tratadas em descarga de vaso sanitário e rega de jardim. XIII Simpósio Luso-Brasileiro de Engenharia Sanitária e Ambiental, Belém 2008.

MARA, D. Domestic wastewater treatment in developing countries. Earthscan. London, 2003.

Oliveira, L. H. Metodologia para implantação de programa de uso racional de água em edifícios. Tese de Doutorado - Escola Politécnica da USP, São Paulo, 1999.

PERONA, J. F. Eficiência do uso da água nas edificações. Monografia (Especialização) - Universidade Federal de Minas Gerais. Belo Horizonte, 2011.

RAUCH, W.; BROCKMANN, D.; PETERS, I.; LARSEN, T. A.; GUJER, W. Combining urine separation with waste design: an analysis using a stochastic model for urine production. Water Research. V 37. 2003.

RICHARDS, L. A. Diagnosis and improvement of saline and alkali soils. United States Salinity Laboratory Staff. United States Department of Agriculture. Agriculture Handbook N ${ }^{\circ}$ 60. Washington, 1954.

RIOS, E. C. S. V. Uso de águas amarelas como fonte alternativa de nutriente em cultivo hidropônico da alface 
(Lactuca sativa). Programa de Pós-graduação em Engenharia Ambiental, universidade Federal do Espírito Santo. Vitória, 2008.

SABESP - Companhia de Saneamento Básico do Estado de São Paulo. Manual de gerenciamento para controladores de consumo de água. Disponível em: <http://site.sabesp.com.br/uploads/file/asabesp_doctos/ Manual\%20do\%20controlador.pdf>. Acesso: 03/02/2013.

SOARES, W. C; ALVES, W. C.; ZANELLA, L.; CHIEKA, A. J. Alternativas simples para coleta de urina em escritório e comparação de sistemas de filtração para obtenção da estruvita visando aproveitamento de nutrientes. $26^{\circ}$ Congresso Brasileiro de Engenharia Sanitária e Ambiental. Porto Alegre, 2011.

ZANCHETA, P. G. Recuperação e tratamento da urina humana para uso agrícola. Dissertação (Mestrado), Programa de pós-graduação em Engenharia Ambiental, Universidade Federal do Espírito Santo. Vitória, 2007.

VINNERÅS, B., PALMQUIST, H.; BALMÉR, P.; JÖNNSON, H. The characteristics of household wastewater and biodegradable solid waste - a proposal for new Swedish design values. Urban Water Journal, v.03, n.01, 2006. 